\title{
Morphology and Molecular Biology : Can the Latter Ignore the Former? An Imaginary Dialogue
}

\author{
Gianpaolo PaPaccio \\ Institute of Anatomy, 2nd University of Naples School of Medicine, Naples, Italy
}

Received March 28, 1994

One point of both major controversy and interest in research is the weight given to a single finding and its interpretation in order to qualify a given treatment as useful or not. For obvious reasons, scholars try to reinforce their own research and field. However, achieving the exact balance and giving the right degree of importance to single findings is quite difficult, especially when they seem to disagree or diverge with others. When this happens, the wisdom of the researcher, and his ability, honesty and independence as a scientist should guide him to avoid taking sides and misinterpreting the results. Unfortunately, this happens only rarely (in research as well), especially when people tend to follow the fashion of the moment. In this situation the "emerging" technique is often exchanged with or overshadows a real "science".

More specifically, at present molecular biology is overshadowing morphology. This makes no sense, because workers in both fields ought to cooperate instead.

To clarify this argument, an imaginary debate between two researchers of different scientific backgrounds but engaged in the same field, i.e. type 1 diabetes, is presented below. It takes place in a laboratory between a morphologist and a molecular biologist who both work on the immunopathology and immuneintervention of type 1 diabetes. Their (imaginary) names are, respectively, Dr. Islet and Dr. Cytokine.

\section{SCENE 1}

Several papers dealing with the ability of several treatments to reduce the incidence of diabetes have been published (WILBERZ et al., 1988; KoLB et al., 1991; Williams et al., 1993); now Dr. Islet, having read them, is seated at his laboratory desk, in fury. He shouts, "My poor islands! Where have they disappeared to? Will they survive future research? Is it possible to leave them out of consideration? How is it possible to speculate on the reduced incidence of diabetes (WILBERZ et al., 1988; WilliAMS et al., 1993), or on its suppression (KoLB et al., 1991) without carefully observing them directly or by observing them but underestimating their pathological appearance? I did not foresee what is now happening, but I can sense dark clouds and storms for the future!" Then he takes the articles and goes to the molecular biology lab next door.

\section{SCENE 2}

Dr. Islet opens the door brusquely and bumps into $\mathrm{Dr}$. Cytokine, who has been assaying a new interleukin (number 1001!).

Dr. Islet: "Well! What are you doing? Do you still think that you'll discover a realiable function for your molecule? Since the discovery of Interleukin-1, hundreds of papers have been published and an infinite number of cytokines discovered with several functions ascribed to them, many in contradiction to each other. Are you able to tell me which of them is, for instance, 'solely' diabetogenic or 'exclusively' protective for diabetes? I mean in vivo, because what exactly these molecules do in vitro is extremely questionable and, above all, happens with difficulty in vivo."

Dr. Cytokine: "Dear friend, what's wrong with you? You seem to be rather vexed. Please, calm down and tell me exactly what has made you so furious."

Dr. Islet: "I understand that you and your collegues tell us stories, you spin yarns and your listeners increase day by day as do your molecules. The truth is that it is hard to contradict your findings because they are skilfully done and the winds of financial support are all blowing in your favour. 
Unlike you, I am forced to cut back on expenditures and observe slide after slide and find proofs and counter-check at all levels of microscopy and immunohistochemistry, but even so my data are poorly considered or they are considered only after your molecules!"

Dr. Cytokine: "What is your temperature? Maybe you have a fever. Who devalued your work? I am convinced that your work has been fundamental for research and is a major part of the knowledge in all research fields, and for diabetes in particular. The only real problem is that you progress slower than we; I mean, that our technique is growing day by day, and allows us to discover many molecules and functions and helps us to understand more in many research fields. You probably should collaborate with us."

Dr. Islet: "You have confirmed my opinion. You are using a mere 'technique' which is not yet a science, but you are already presumptuous enough to advise me to collaborate with you. My science is the oldest, and is extremely precise. You should beg me just to be admitted into my laboratory in order to give support to your vague, inaccurate and conflicting data!"

Dr. Cytokine: “I won't accept your provocations. Our methods are accurate and increase knowledge in science. I imagine that you have read some articles in which you were interested and you found some opinions or results that did not please you. Let me know what made you so angry, and then discuss it with me without your preconceived ideas."

Dr. Islet: "O.K. I agree with you. I think that the best idea is for you to read these articles together with some of my articles on the same topic (PAPACCIO, 1993a, b; PAPACCIO et al., 1993, 1994) and arrange a meeting for tomorrow for a calm and objective discussion. What about 5 o'clock in Hall Number 5?"

Dr. Cytokine: "That's fine with me. See you tomorrow and have a good night's rest."

\section{SCENE 3 (Hall No. 5)}

Dr. Islet is early. He has been imagining what Dr. Cytokine might think and say about his morphological evaluations, turning all this over in his mind: "He's surely convinced that molecular biology fulfils any study and that morphology is just optional."

Dr. Cytokine arrives whistling and says, "Good morning dear colleague! Did you sleep well? Are you relaxed? I read the articles you gave me and I found them interesting. The only remark that stood out concerns the discrepancy between biochemical and morphological data. Maybe that is the object of you dispute. Am I right?”

Dr. Islet: "Oh! As I imagined you are a very clever man! That is the major point: a big and incomprehensible discrepancy which reflects a way of research that allows the abasement of morphology."

Dr. Cytokine: "I see. You understand that in those papers biochemical results are quite 'positive', that is, in favour of a beneficial effect for treatment, but morphological observations only say that islet infiltration is not counteracted or it is in progression. This is quite difficult to interpret."

Dr. Islet: "You have further focused on the matter. The degree of insulitis is difficult to interpret by you and by people that do not understand-or do not want to understand - this as the more evident sign of an attack on islet $B$ cells: it is the expression of the presence of an autoimmune inflammation which is directed against insulin-containing B cells, and when it is not suppressed or prevented, it means a negative forecast for the development of diabetes. As you can see, the interpretation is extremely easy! The problem is how to correctly interpret the diverging results and how to balance them."

Dr. Cytokine: "I'm not convinced that the persistence of insulitis indicates a negative forecast. As you know, insulitis may revert and islet B cells may replicate; in fact, a de novo genesis of these elements has been reported (SwENNE, 1992). Moreover, in April, 1993, I attended the 12th International Immunology and Diabetes Workshop in Orlando, Florida (MACLAREN and LAFFERTY, 1993), and I heard that most NOD mice remain diabetes prone but develop nondestructive lesions in their pancreases after immunostimulation or immunosuppression. These lesions coincide with the peri-islet infiltration, which, therefore, could be seen to be protective!".

Dr. Islet: “That doesn't surprise me. I guessed that differences in the degree of insulitis would be of great importance and should be interpreted differently. Your arguments only enhance my opinion that further and more detailed investigations must be performed in order to correctly assess the B cell survival, which may include ultrastructural observations. This requires cooperation between molecular biologists and morphologists: we must collaborate in the future, in order to avoid misinterpretations and so lend strong support to research."

Dr. Cytokine: “. ... and to cool your anger ... and make peace among researchers."

Dr. Islet: "This is only for the supreme interest of science."

A handshake settles the brief but useful meeting, at which Islet and Cytokine seem to have promised peace and cooperation. 


\section{REFERENCES}

KoLB, H., U. KIESEL, K.-D. KRÖNCKE and V. KOLB-BACHOFEN: Suppression of low dose streptozotocin induced diabetes in mice by administration of a nitric oxide synthase inhibitor. Life Sci. 49: 213-217 (1991).

MACLAREN, N. and K. LAFFERTY: The 12th International Immunology and Diabetes Workshop (Orlando, Florida). Diabetes 42: 1099-1104 (1993).

Papaccio, G.: Gangliosides prevent insulitis but not B cell destruction in low-dose streptozocin-treated mice. Diabetes Res. Clin. Pract. 19: 9-15 (1993a).

: Insulitis and islet microvasculature in type 1 diabetes. Histol. Histopathol. 8: 751-759 (1993b).

Papaccio, G., V. Mezzogionno and G. Chieffi Baccari: In vivo effects of gangliosides on NOD mice. Acta Anat. 147: 168-173 (1993).

Papaccio, G, V. Esposito and F. A. Pisanti: Administration of a nitric oxide synthase inhibitor does not suppress low-dose streptozocin-induced diabetes in mice. Int. J. Pancr. (1994, in press).
Swenne, I.: Pancreatic B-cell growth and diabetes mellitus. Diabetologia 35: 193-201 (1992).

Wilberz, S., L. Herberg and A. E. Renold: Gangliosides in vivo reduce diabetes incidence in NOD mice. Diabetologia 31: 855-857 (1988).

Williams, A. J. K., P. E. Beales, J. Krug, E. Procaccini, A. Signore, S. Xu, E. A. M. Gale and P. Pozzilli: Tolbutamide reduces the incidence of diabetes mellitus, but not insulitis, in the non-obese-diabetic mouse. Diabetologia 36: 487-492 (1993). 